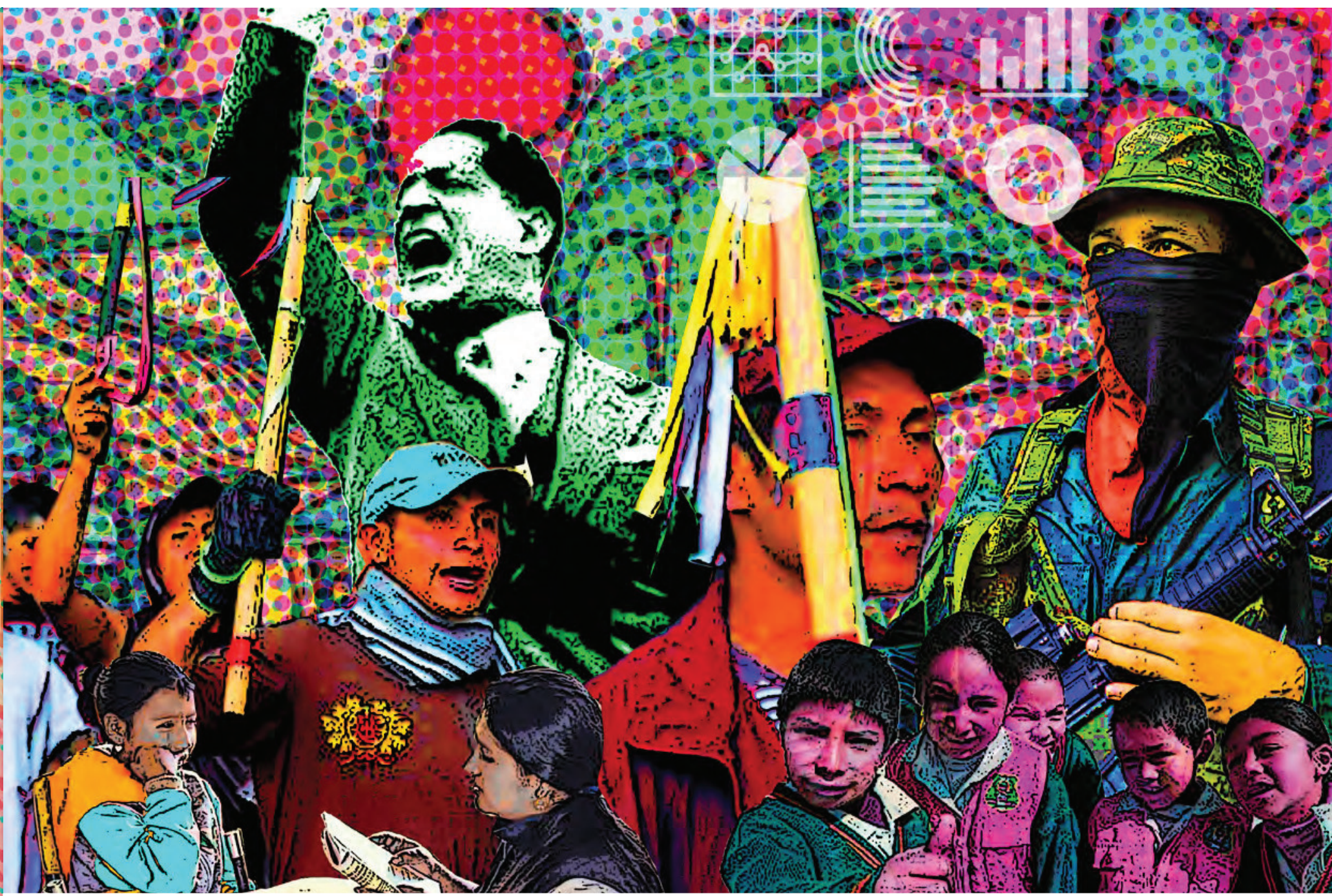

\title{
Los pasados violentos en los relatos de historias de vida de docentes del \\ Distrito en la ciudad de Bogotá
}

THE VIOLENT PASTS IN THE STORIES OF LIFE STORIES OF DISTRICT TEACHERS IN THE CITY OF BOGOTÁ

O PASSADO VIOLENTO NAS HISTÓRIAS DE HISTÓRIAS DE PROFESSORES DO DISTRITO NA CIDADE DE BOGOTÁ 
TEMA: : IMPORTANCIA DE LA INVESTIGACIÓN DE LOS MAESTROS Y MAESTRAS

\section{Diana Esperanza Páez Robayo ${ }^{1}$}

Candidata a Doctora, Doctorado Interinstitucional en Educación DIE, Universidad Distrital Francisco José de Caldas; Magíster en Educación, Universidad Externado de Colombia. Integrante, como estudiante, del Grupo de Investigación de Educación y Cultura Política; Coordinadora, Colegio Carlos Pizarro Leongómez, Secretaría de Educación de Bogotá; correo electónico: profepolitologa@gmail.com

DOI https://doi.org/10.36737/01230425.n38.2020.2317

Fecha de recepción: 3 de febrero de 2020 / Fecha de aprobación: 15 de mayo de 2020

\section{Resumen}

El presente artículo hace parte de los resultados finales de la Tesis Doctoral titulada Subjetividad política y memorias de maestros: entre la violencia política y la escuela ${ }^{2}$, que aborda la relación, entre las memorias de historias de vida de maestros vinculados al Distrito de Bogotá, y situaciones de pasados violentos y traumáticos ligados a la violencia política ${ }^{3}$, partiendo de un enfoque cualitativo y una metodología que incluye la investigación biográfico-narrativa.

Palabras clave: Memorias, historias de vida de maestros, investigación biográfica narrativa.

\section{Abstract}

This article is part of the final results of the Doctoral Thesis entitled Political Subjectivity and Teacher Memories: Between Political Violence and the School, which addresses the relationship between the memories of life stories of teachers linked to the Bogotá District and past situations and traumatic violence-related political violence from the qualitative approach with the focus of biographical-narrative research.

Keywords: Memories, teacher life stories, narrative biographical research.

\section{Resumo}

Este artigo é parte dos resultados finais da Tese de Doutorado intitulada Subjetividade Política e Memórias de Professores: Entre Violência Política e a Escola, que aborda a relação entre as memórias de histórias de vida de professores vinculadas ao Distrito de Bogotá e situações passadas. e violência traumática relacionada à violência política a partir da abordagem qualitativa, com foco na pesquisa biográfico-narrativa.

Palavras-chave: Memórias, histórias de vida de professores, pesquisa biográfica narrativa.

2. Desarrollada en la Universidad Distrital Francisco José de Caldas para el Doctorado Interinstitucional de Educación DIE, Énfasis en Historia de la Educación, Pedagogía y Educación Comparada, Línea: Formación Política y Memoria Social; dirigida por el profesor Dr. Diego Hernán Arias Gómez.

3. Apartes de este artículo fueron socializados en el XIX Congreso Internacional de Educación Histórica en la Ciudad de Cali, Colombia, 14 al 16 de agosto de 2019. 


\section{Introducción}

E 1 presente artículo aborda el recorrido desarrollado durante el trabajo de campo vinculado a la tesis doctoral Subjetividad política y memorias de maestros: entre la violencia política y la escuela, el cual tuvo como objetivo analizar la configuración de las subjetividades políticas de un grupo de maestros de la Secretaría de Educación de Bogotá, que han atravesado situaciones de violencia política, a partir de sus memorias y su relación con las apuestas ético-políticas que expresan frente a la enseñanza de pasados recientes; buscando responder una pregunta de investigación: ¿Cómo es la subjetividad política de maestros que han vivido la violencia política en Colombia y de qué manera inciden sus memorias en la enseñanza de los pasados recientes?

En un primer momento, este artículo aborda el recorrido de construcción del corpus documental que sustenta la pertinencia del proceso investigativo; en segundo lugar, expone la ruta seguida para consolidar las categorías teóricas que le sustentan $\mathrm{y}$, a continuación, plantea la propuesta metodológica basada en el enfoque cualitativo; finalmente, presenta algunas conclusiones preliminares, analizando las implicaciones de la investigación del maestro en el ejercicio de la docencia.

Es importante indicar que ahora mismo el trabajo de campo se desarrolla en la ciudad de Bogotá y ha contado con la participación de maestros y maestras de diferentes áreas de conocimiento, incluyendo los dos estatutos que rigen la carrera docente a nivel nacional para preescolar, básica primaria, básica secundaria y media (Decretos 2277 del 1979 y 1278 del 2002); además, se incluyen diferentes ejercicios de acción política y social del gremio docente y de otras áreas de acción.

\footnotetext{
4. "El posacuerdo hace referencia al inmediato período que se abre para Colombia tras la firma del esperado acuerdo de paz con las FARC, configurando a partir de allí una nueva serie de políticas públicas que tendrán como novedad la finalización de una situación conflictiva directa respecto a este grupo insurgente. El posacuerdo implica entonces la reconfiguración de la agenda política de gran parte del país en el corto y mediano plazo, abarcando de manera coordinada los campos de la seguridad, la justicia, la economía y la cooperación, en aras de consolidar la construcción de la paz o peacebuilding, en una perspectiva que va más allá del mediano término y se proyecta en el largo plazo" (Cepeda, 2016, p. 218).
}

\section{Proceso investigativo: Corpus y pertinencia de las historias de vida como alternativa investigativa}

En el marco del proceso de tesis doctoral, se buscó analizar la configuración de subjetividades de maestros que han vivido situaciones de violencia política relacionadas con sus apuestas éticopolíticas. La inquietud parte de dos perspectivas: 1) La importancia de reconocer, en el marco del conflicto armado, la forma en que la violencia política atraviesa a los sujetos maestros, tomando como referente sus posturas políticas; y 2) El interés porque los temas de investigación doctorales en el campo de investigación en educación, específicamente para la línea de formación política y memoria social, en la que se inscribe este trabajo, tomen como punto de referencia el entramado de relaciones que operan en la escuela alrededor de la violencia política, considerando que, desde el papel de investigadora y directiva docente, se enfrentan retos de carácter político y pedagógico.

El trabajo toma como punto de partida la relevancia y pertinencia de los temas sociales, políticos, históricos y pedagógicos en el escenario del post acuerdo, tras la firma de los tratados de paz entre el Gobierno Nacional y el grupo guerrillero de las FARC $\mathrm{EP}^{4}$, que abre el camino hacia una amplia reflexión en cada una de las esferas de la sociedad colombiana, entre ellas la escuela, especialmente uno de sus actores: los maestros; que deben ser visibilizados, escuchando su voz para que puedan narrar, desde su perspectiva, la incidencia de la violencia en su constitución como sujetos y su labor docente.

El estado del arte fue un primer momento del ejercicio investigativo e incluyó un corpus de 65 investigaciones, 39 de carácter nacional y 26 internacionales, obtenido desde bases de datos de bibliotecas y universidades con facultades de educación y ciencias sociales, así como desde tesis de doctorado y maestría, artículos de investigación de maestría y doctorado, libros y capítulos de libros e informes y proyectos de investigación. Una vez reunido el material se plantearon cuatro grupos, teniendo como parámetro central la cercanía de las narraciones de vida de los maestros a situaciones relacionadas con conflicto armado y/o violencia política, lo cual permitió definir cuatro vertientes analíticas que recogen los trabajos consultados y permiten su análisis, a saber:

1. Historias de vida de maestros que describen algún momento de su vida relacionado con un hecho o acontecimiento del conflicto armado y la violencia política.

2. Historias de vida de maestros que viven y trabajan en zonas de conflicto armado. 


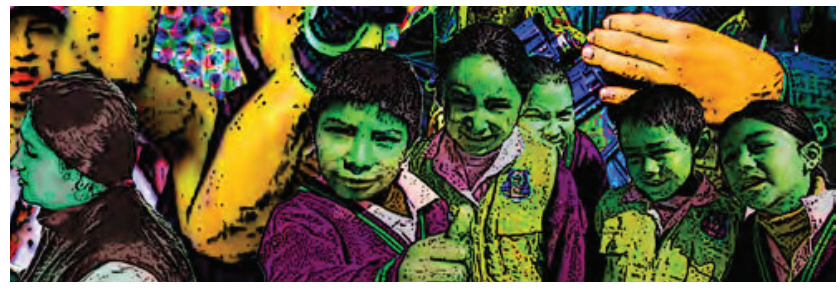

3. Historias de vida de docentes que plantean ejercicios reflexivos en el aula vinculados al conflicto armado y la violencia política.

4. Historias de vida de maestros con una apuesta ético-política.

Así, partiendo de la importancia de retomar la narración del sujeto para constituirla como fuente primaria de la reconstrucción de un momento histórico, las historias de vida de los docentes florecen como alternativa investigativa en el campo de la educación (Goodson, 2004), constituyéndose como herramientas investigativas que dan voz al sujeto docente para analizar más ampliamente un contexto y una posición.

[...] las historias de vida de profesores, con la finalidad de comprender trayectorias profesionales vinculadas a determinadas áreas o procesos históricos, consiste en localizar el propio relato del profesor o profesora en el marco de un análisis contextual más amplio, o dicho en palabras de Stenhouse, construir "una narrativa de la acción dentro de una teoría del contexto" (Goodson, 2004, p. 22).

Desde esta perspectiva, las historias de vida funcionan como herramientas investigativas del trabajo en educación, especialmente útiles para reconstruir la trayectoria del docente, no solo desde su lugar como relator de un momento, sino como sujeto narrador con una postura frente al contexto. Por consiguiente, las historias de vida de los maestros evidencian los cruces en su formación y quehacer docente con situaciones relacionadas con el conflicto armado y la violencia política, otorgándoles: “(...) no sólo visibilidad, sino un nuevo sentido: el de prácticos reflexivos o intelectuales críticos que toman sus propias trayectorias como

2. Según Martínez y Cubides (2012), cuando se habla del "poder instituido" se encierran las formas de ejercicio del Estado y su organización institucional, así como a todas las formas de ejercicio de poder que buscan mantener un orden establecido como el natural; lo "instituyente" emerge como capacidad de construcción y acción aunque es posible tomar por separado lo instituido y lo instituyente. fuente no sólo de experiencia sino de conocimiento y saber pedagógico" (Goodson, 2004, p. 25).

\section{Construcción, deconstrucción y emergencia de las categorías}

Luego de identificar la línea analítica que se desprendía del agrupamiento del corpus documental, se establecieron cuatro categorías teóricas: Subjetividad política; memorias; violencia política y enseñanza de los pasados recientes. La "subjetividad política" se comprende como la "agencia entre lo instituido y lo instituyente", labor conveniente porque permite reconocer al sujeto frente a su ejercicio de la política; como indica Touraine (2006), el sujeto implica una acción política de manifestación frente al orden establecido y las alternativas de acción, por lo que es:

[...] entonces, eminentemente político y, si su acción tiene efectos sociales o económicos, se manifiesta a través de categorías directamente políticas. Se trata, ante todo, de afirmar una voluntad colectiva frente a un sistema social y político que se define como natural (p. 40).

Los maestros, como sujetos políticos atravesados por pasados recientes, colmados de altas cargas de violencia, trauma y dolor, constituyen formas de subjetividad política que emergen frente a los hechos vividos; por tanto, no se trata de figuras homogéneas e invariables, sino de una constante respuesta a las contingencias y tensiones establecidas en las relaciones sociales, políticas y económicas; ejercicios alternativos frente a los hechos de violencia política que han atravesado su vida y su ejercicio docente, como formas de reconocer su poder de acción frente a lo instituido y lo instituyente ${ }^{5}$; así:

La subjetividad política es producción de sentido y condición de posibilidad de un modo de 'ser' y 'estar' en sociedad, de asumir posición en esta y hacer visible su poder para actuar. Posición que está inscrita en un campo de fuerzas complejo que exige al sujeto deconstruirse y reconstruirse permanentemente en esa tensión permanente entre lo instituido y lo instituyente (Martínez y Cubides, 2012, p. 176).

Por su parte, la categoría de "memorias" se establece como línea de análisis que se nutre de la narración de los sujetos y tiene, por antonomasia, una carga emotiva, política y hasta de denuncia, buscando visibilizar hechos y actores. Su estado de fuente de construcción simbólica lleva a que las memorias se dispongan como puente para relacionar una dimensión de carácter privado y una 
pública; por tanto, las memorias de los sujetos sobre la incidencia de la violencia política en sus relatos de vida y en la configuración de una subjetividad política, permiten recorrer un camino desde lo singular a lo colectivo. Entonces, como afirman Franco y Levin (2007), el concepto de memoria permite un tejido entre lo íntimo y lo social, entre diversos relatos que, al compartirse, construyen sentidos colectivos; la memoria abre el espacio para que personas y grupos puedan narrar lo vivido, perfilándose como herrramienta clave para dar sentido de pertenencia y de enunciación (Jelín, 2002).

No obstante, las memorias no solo cumplen con la función de reconstruir el relato, tienen un componente ético que les permite visibilizar las identidades sustraídas, cumpliendo así con su función

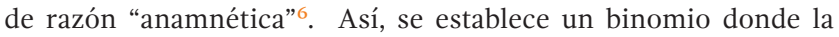
historia puede reconocer la importancia de las subjetividades; como indicaron Franco y Levin, no se trata de que la historia tenga como única fuente a la memoria y el relato oral, pero sí pueden constituirse como "la base de una vertiente muy rica y en pleno auge de una historiografía que toma la subjetividad como un objeto de estudio tan legítimo como cualquier otro" (Franco y Levin, 2007, p. 9)

Ahora, continuando, la categoría de "violencia política" es definida aquí desde la división planteada por Pécaut (2015), quien establece cuatro períodos para trabajar el conflicto interno armado: 1) Entre los años 1920 y 1936, con las movilizaciones campesinas organizadas en torno a los problemas agrarios; 2) La época de la violencia de los años 1950, cuyo resultado fue el tercer momento; 3) La etapa que comprende los años entre 1960 y 1975, cuando se da el nacimiento de diversas guerrillas; y 4) El narcotráfico, paramilitarismo y reorganización de la lucha insurgente, que llega hasta la actualidad.

De acuerdo con ello, se acoge también la perspectiva de la violencia política desde las ecologías violentas, porque reconoce este hecho como una acción que, inmersa en el conflicto interno armado, busca la eliminación del adversario en todas las esferas de la constitución del sujeto, especialmente de las apuestas éticopolíticas que le identifican en un colectivo, con el fin de lograr unos idearios políticos y sociales.

[Es la violencia] ejercida como medio de lucha político-social, ya sea con el fin de mantener, modificar, sustituir o destruir un modelo de Estado o de sociedad, o también con el fin de destruir o

2. Para Ricoeur (2002), la razón anamnética constituye un imperativo ético, reconocer el crimen, lo traumático del hecho y las huellas que dejó a nivel individual y social. reprimir a un grupo humano con identidad dentro de la sociedad por su afinidad social, política, gremial, étnica, racial, religiosa, cultural o ideológica, esté o no organizado (CINEP, 2008, p. 5).

Por último, la categoría de "pasados recientes" se refiere a hechos pretéritos cargados de intenso dolor y de difícil asimilación para la sociedad actual. Ellos destacan una tensión vinculada a las diferencias, límites, alcances y diálogos entre historia y memoria, así como la emergencia de esta última en diversas esferas de la sociedad. En tal contexto, desde la perspectiva sociocultural trabajada por Herrera, Ortega, Olaya y Cristancho (2012), y Arias (2016), toma fuerza la categoría de enseñanza de los pasados recientes, que basa su análisis en las relaciones surgidas en el devenir histórico de América Latina desde el siglo XX y comienzos del XXI, señalando diversas problemáticas como la violencia política, que ha sido determinante en las expresiones culturales de la política nacional y continental; al tiempo, la enseñanza de pasados recientes presenta las siguientes características:

1. Junto a las reflexiones pedagógicas, esta enseñanza se establece como fundamento académico, ético y político, adquiriendo suma importancia en la escuela, porque es en este espacio (formal o no formal) donde se desarrollan visiones, aproximaciones y análisis sobre la memoria, los pasados recientes y el tratamiento que se da a la violencia política; por tanto, la escuela es un escenario clave.

Por la fuerza que continúa teniendo como lugar de formación, a pesar de las transformaciones en curso, puesto que los individuos pasan gran parte de sus primeros años de infancia y juventud en los recintos escolares durante horarios extendidos, y porque la escuela continúa siendo uno de los indicadores de inclusión ciudadana en los regímenes democráticas (Herrera y Pertuz, 2016, p. 37).

2. Es pertinente investigar sobre la violencia, los procesos de subjetivación, las memorias y los sujetos maestros, tomándoles como punto de reflexión; ello permite reconocer a los actores maestros y al espacio escolar como espacios de encuentro de diversos sujetos y formación de subjetividades políticas.

3. Visibilizar a los sujetos con diferentes experiencias frente a la violencia política, en este caso los maestros, permite comprender la forma en que "vivencian" lo ocurrido en sus procesos de enseñanza y aprendizaje, con sus posturas éticopolíticas y en sus prácticas sociales (Herrera, Ortega, Olaya y Cristancho, 2012). 
TEMA: : IMPORTANCIA DE LA INVESTIGACIÓN DE LOS MAESTROS Y MAESTRAS

\section{El enfoque biográfico narrativo: Narrar la historia de nuestra vida como auto- interpretación de lo que somos}

Como se expuso anteriormente, las categorías empleadas, subjetividad política, memorias, violencia política y pasados recientes, parten de la experiencia de los sujetos, de un contexto social y político determinado, lo cual imprime la necesidad de analizar dichas experiencias en el campo investigativo; así, resulta evidente que la investigación cualitativa es la perspectiva que permite este acercamiento al sujeto, porque no sigue un único parámetro de indagación, sino que utiliza una amplia gama de intervenciones para reconocer la diversidad de los sujetos.

[...] la investigación cualitativa se interesa, en especial, por la forma en la que el mundo es comprendido, experimentado, producido; por el contexto y los procesos; por la perspectiva de los participantes, por sus sentidos, por sus experiencias, por sus conocimientos y sus relatos (Vasilachis, 2006, p. 29)

En la presente investigación el enfoque cualitativo no solo permite interpretar las perspectivas subjetivas de los participantes, lo cual, unido a la perspectiva teórica, supone una comprensión particular de los fenómenos (Vasilachis, 2006); sino que, debido a la producción y aplicación de métodos flexibles, facilita la generación de datos contextualizados, llevando a un análisis y explicación de "la complejidad, el detalle y el contexto" (Vasilachis, 2006, p. 27). Así, lo pragmático y la cercanía con la experiencia de las personas invitan a un ejercicio riguroso de recolección de información basado en su cotidianidad, mientras, desde la perspectiva del sujeto, se privilegian las palabras y los comportamientos del fenómeno social a estudiar.

De acuerdo con lo anterior, este enfoque se ajusta al propósito de comprender el significado que las personas dan a sus vidas, acciones y a los sucesos de violencia política que han vivido, mientras permite identificar la incidencia de estas acciones en sus configuraciones subjetivas como sujeto y sujeto maestro, haciendo evidentes sus posturas teóricas y apuestas ético-políticas frente al tratamiento de dichos temas en la escuela y en la cotidianidad; junto a ello, el enfoque cualitativo llevó a trabajar desde la perspectiva de la investigación biográfico-narrativa, que comprende:

[...] un extenso conjunto de modos de obtener y analizar relatos referidos a historias de vida, historia oral, escritos y narraciones autobiográficas, entrevistas narrativas, testimonios; es decir, cualquier forma de reflexión oral o escrita que utiliza la experiencia personal en su dimensión temporal (Bolívar, Domingo y Fernández, 2001, p. 18).

Mediante el establecimiento de un espacio de diálogo con los maestros, la investigación biográfico-narrativa permitió acercarse a los objetivos trazados a partir de los siguientes instrumentos.

Tabla 1. Instrumentos proporcionados por la investigación biográfico-narrativa

Instrumento

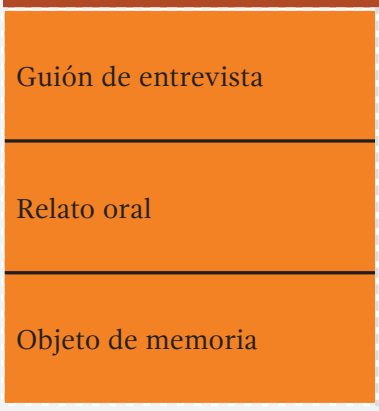

\section{Propósito}

Reconstruir las memorias de los maestros frente a diversos sucesos y vivencias presentes en su historia de vida, que configuraron sus subjetividades políticas

Reconstruir las memorias de lo que evocan las diferentes imágenes de la historia de Colombia frente a la situación personal, política u organizativa

Relatar, desde objetos de la memoria, situaciones, sensaciones, espacios, etc., que permitan identificar modos de configurar la propia subjetividad política 


\section{Resultados preliminares de la investigación}

A continuación, se tomarán las categorías de "subjetividad", "memorias” y "educación” para exponer una aproximación general a lo encontrado durante el proceso investigativo.

\section{La subjetividad, relación de lo vivido con las apuestas por un buen vivir desde el presente}

Las acciones realizadas con los maestros durante esta investigación utilizaron como vehículo los instrumentos propuestos en el trabajo de campo; así, sus relatos permiten identificar diferentes hechos sociales, políticos y económicos de la estructura histórica del país, que han determinado su trayectoria familiar y personal y reflejan perspectivas de acción y participación con alta carga social, las cuales se materializan en propuestas de trabajo político y educativo expresadas como descontento frente a lo instituido. Esto lleva a una aproximación analítica que evidencia una relación proporcional entre la vida del país, específicamente las acciones de violencia política, y las diversas facetas que se han vivido como sujetos, de manera individual y en contexto con los otros; todo ello tiene gran significado, porque la violencia vivida es producto de un ejercicio instituyente que reclama al poder establecido.

\section{Las memorias y la construcción del presente: \\ Silencios, pensamientos y recuerdos}

Es posible hacer un recorrido por diversos hechos del país a partir de las memorias narradas por los docentes, pero, al tiempo, se identifican silencios, pensamientos, posturas y recuerdos de lo acaecido que toma vida o se prolonga como silencio desde el relato presente. $\mathrm{Al}$ respecto, es importante destacar el recorrido de la memoria docente en diversos lugares de Bogotá, pues expresa momentos de las escuelas de la ciudad en tiempos determinados y mediante hechos históricos que se cruzan en espacios y momentos comunes de los maestros; por ejemplo: la incidencia del paro de 1977; los encuentros del movimiento estudiantil de secundaria o la toma del Palacio de Justicia.

Tales acontecimientos llevan a acuerdos en la memoria de los diversos sujetos, quienes, desde el presente, lograr así establecer conexiones entre sucesos personales e históricos para darles un significado, concretando estructuras narrativas caracterizadas por una secuencia que establece espacios, tiempos, contextos, causas, motivos y consecuencias; al tiempo, la narrativa resultante es "una forma específica de discurso organizado en torno a una trama argumental, secuencia temporal, personaje/s, situación" (Bolívar, Domingo y Fernández, 2001, p. 20).
Las historias de vida enunciadas por los maestros, a partir de sus memorias sobre la violencia política, son un vehículo fundamental para comprender la importancia de los pasados recientes como elemento transversal en la configuración de una forma de ser y estar en la sociedad como maestro; es decir, a la hora de ver la multiplicidad de subjetividades políticas que se han constituido a partir de la vivencia de la política y de la violencia política como línea del conflicto armado, las cuales han configurado un campo donde no solo se transgrede lo físico del sujeto, sino la consolidación de su pensamiento y de su ser en lo social, generando una diversidad de situaciones, confrontaciones y dilemas (Páez, 2019a, p. 6).

\section{La educación, una apuesta de cambio y construcción social}

De acuerdo con lo planteado, hay un reconocimiento de la educación como espacio de formación y de transformación política y social. En este sentido, un alto porcentaje de los maestros actores de esta investigación asumió la docencia en el Distrito como opción de vida, como un espacio amplio y autónomo de trabajo en el cual, a partir de sus vivencias organizacionales y apuestas ético-políticas, les resulta posible concretar nuevas formas en la escuela, en las áreas de conocimiento y en otros espacios, como los comunales y sindicales, manteniendo la coherencia política y de trabajo narrada en sus relatos.

\section{Reflexiones y conclusiones preliminares}

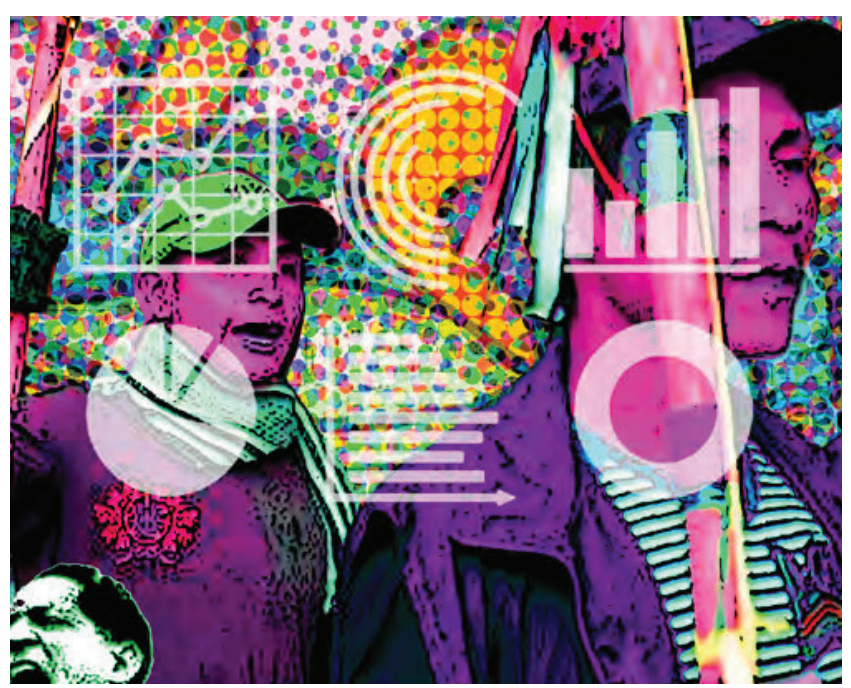


TEMA: : IMPORTANCIA DE LA INVESTIGACIÓN DE LOS MAESTROS Y MAESTRAS

El trabajo realizado llevó a investigar el interior del espacio escolar, algo muy valioso, pues dicho contexto brinda una amalgama de actores, situaciones, prácticas y experiencias que permiten indagar, analizar, aportar, debatir, construir y deconstruir; ejercicios que, a su vez, resaltan la riqueza de la escuela al no definirle únicamente desde su lugar como espacio para el proceso de enseñanzaaprendizaje, sino destacando que en ella hay gran diversidad de pensamiento y acción, que se trata de un escenario que brinda la oportunidad para crear con el otro y los otros desde la pedagogía, la política, la didáctica y lo social.

Al tiempo, es fundamental reconocer, como lo hace el corpus compuesto por 65 documentos, que solo hasta 1997 surgen investigaciones que dan cuenta de procesos de la historia reciente y de su relación con la historia de vida de los docentes. Por tanto, el recorrido realizado por la relación entre historias de vida de docentes y su vínculo con el conflicto armado y la violencia política, permite destacar los relatos de vida como alternativas para reconstruir momentos desde la perspectiva de quien los vivió; igualmente, lleva a reconocer la trayectoria de la persona para identificar las diversas situaciones que ha vivido y que configuran su subjetividad política (Páez, 2018, p. 137).

Las historias de vida de los maestros son un campo investigativo que permite acercarse a los pasados recientes, mientras se considera como actor esencial la voz del sujeto; este trabajo reconoce la singularidad de los maestros que hacen parte de la Secretaría de Educación de Bogotá, lo particular de sus vidas, situaciones y apuestas por procesos educativos de calidad, de carácter pedagógico y político que no naturalizan la guerra, sino que la cuestionan ofreciendo, desde su quehacer, nuevas respuestas a una violencia que parece dada; por tanto, la constitución de la subjetividad política del maestro está atravesada por la relación entre educación y política, que va más allá de la organización propia de las políticas educativas y de su correspondencia con el Estado y la sociedad (Martínez, 2008).

Así, la política en el espacio escolar, como ejercicio de acompañamiento de sujetos, trasciende la formación ciudadana buscando materializar acciones reales, que los maestros puedan concretar como sujetos políticos, pues se asume que son seres políticos "con capacidad para entregar y resolver los conflictos, tomar decisiones, proponer y optar, actuar en instancias de decisión, aportar significativamente a la construcción de nuevos órdenes sociales y políticos" (Martínez, 2008, p. 113).

La pertinencia de esta investigación no solo radica en indagar por la configuración de subjetividades políticas de los maestros que han vivido violencia política, y su aporte a la escuela a partir del tratamiento de los temas de pasados recientes, sino en apropiarse de un diseño metodológico coherente con las apuestas teóricas (Páez, 2019b, p. 9). Así, la investigación permite validar la importancia del relato biográfico narrativo, para comprender la forma en que los maestros "vivencian" lo ocurrido en sus procesos de enseñanza y aprendizaje, con sus posturas ético-políticas y en sus prácticas sociales.

En suma, este trabajo sobre las historias de vida de los maestros del Distrito permite reconocer su voz y el potencial de formación presente en la escuela bogotana; mientras, al tiempo, destaca la riqueza pedagógica en la ciudad, pues se cuenta con profesores que se han configurado como sujetos políticos yendo más allá de la violencia política vivida, hasta consolidarse como actores que enuncian lo experimentado desde un sentido de transformación, convirtiendo a la escuela, desde su quehacer docente, en un espacio de construcción con otros.

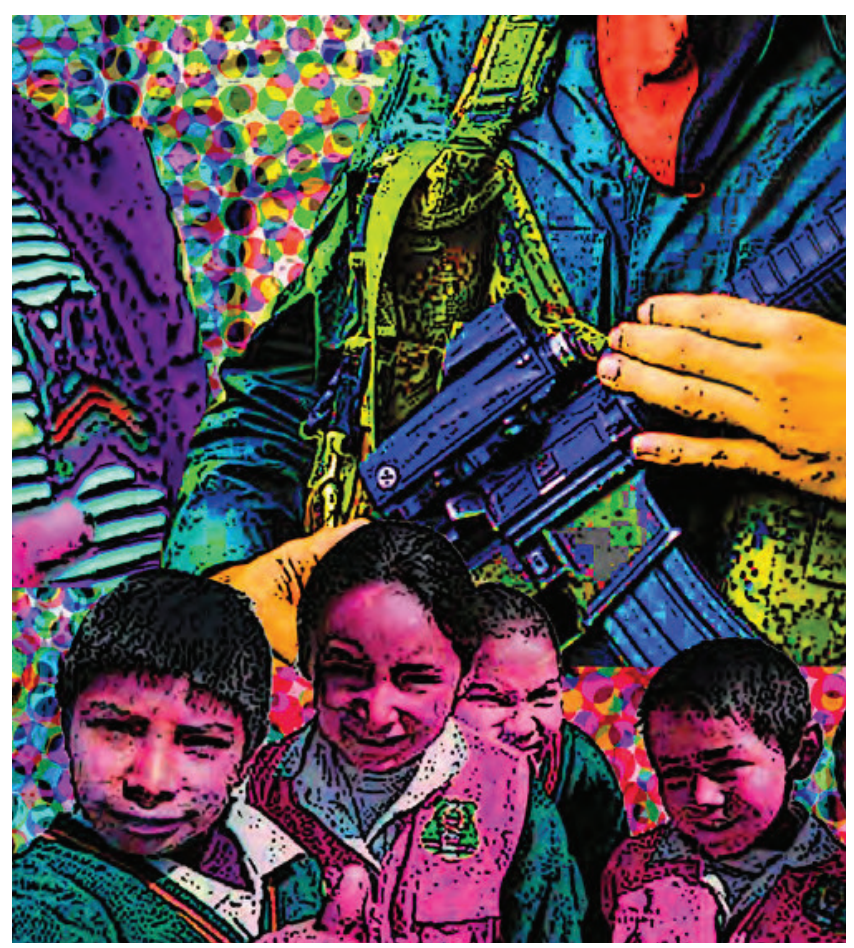




\section{Referencias}

AA.VV. (2015). Contribución al entendimiento del conflicto armado en Colombia. La Habana: Comisión Histórica del Conflicto y sus Víctimas.

Aguilar, P. (2008). Políticas de la memoria y memorias de la política. El caso español en perspectiva comparada. Madrid: Alianza. Arias, D. (2016). La violencia política y el conflicto armado en el aula. Una mirada a los estudios sobre Colombia.

Bolívar, A., Domingo, J., y Fernández, M. (2001). La investigación biográfico-narrativa en educación. Madrid: La Muralla.

Bonilla, E., y Rodríguez, P. (1997). Más allá del dilema de los métodos. La investigación en las ciencias sociales. Bogotá: Norma.

Centro de Investigación y Educación Popular (CINEP). (2008). Marco conceptual, banco de datos, Derechos Humanos y violencia política. Bogotá: CINEP.

Franco, M., y Levín, F. (2007). El pasado cercano en clave historiográfica. Historia reciente: perspectivas y desafíos para un campo de construcción. Buenos Aires: Paidós, pp. 31- 65.

Herrera, M., y Pertuz, C. (2016). Educación y políticas de la memoria sobre la historia reciente de América Latina. Revista Colombiana de Educación, No. 71, pp. 79-108. DOI: https://doi.org/10.17227/01203916.71rce79.108

Herrera, M., y Vélez, G. (2014). Formación política en el tiempo presente: ecologías violentas y pedagogía de la memoria. Revista Nómadas, No. 41, pp. 149-165.

Herrera, M., Ortega, P., Olaya V., y Cristancho, J. (2012). Configuración de subjetividades y constitución de memorias sobre la violencia política. Una promesa de acción en torno a la cultura. En Piedrahita, C., Díaz, A., y Vommaro, P. (Comp.), Subjetividades políticas: desafíos y debates latinoamericanos (pp. 155-167). Bogotá: Universidad Distrital Francisco José de Caldas.

Jelin, E. (2002). Los trabajos de la memoria. Madrid: Siglo XXI.

Martínez, C. (2008). Redes pedagógicas: la constitución del maestro como sujeto político. Bogotá: Cooperativa Magisterio.

Martínez, C., y Cubides, J. (2012). Acercamientos al uso de la categoría de "subjetividad política” en procesos investigativos. En Piedrahita, C., Díaz, A., y Vommaro, P. (Comp.), Subjetividades políticas: desafíos y debates latinoamericanos (pp. 169189). Bogotá: Universidad Distrital Francisco José de Caldas.

Páez, D. (2018, Julio-Diciembre). El conflicto armado, la violencia política y la escuela: perspectivas desde las historias de vida de los docentes. Clío \& Asociados. La historia enseñada, No. 27, pp. 127-139. DOI: https://doi.org/10.14409/cya. v0i27.7665

Páez, D. (2019a). Subjetividad política: relación entre las historias de vida de docentes, la violencia política y los pasados en conflicto. Trabajo presentado en el VIII Encuentro Internacional de Historia Oral y Memorias: "Lecturas críticas, voces diversas y horizontes políticos en el mundo contemporáneo”, Abril, Bogotá.

Páez, D. (2019b). Subjetividad política: categoría para la comprensión de la vivencia de la violencia política en los relatos de historias de vida de maestros. Revista Noria, Investigación Educativa, Vol. 3, No. 1.

Pécaut, D. (2015). Una lucha armada al servicio del statu quo social y político. En AA.VV., Contribución al entendimiento del conflicto armado en Colombia (pp. 599-651). La Habana: Comisión Histórica del Conflicto y sus Víctimas.

Ricoeur, P. (2000). Historia y memoria. La escritura de la historia y la representación del pasado. Annales, Histoire. Sciences Sociales, 55(4), pp. 731-747. DOI: https://doi.org/10.3406/ahess.2000.279877

Ruiz, A., y Prada, M. (2012). La formación de la subjetividad política. Propuestas y recursos para el aula. Buenos Aires: Paidós.

Touraine, A. (2006). ¿Podremos vivir juntos?: Iguales y diferentes. México: Fondo de Cultura Económica.

Vasilachis, I. (2006). Estrategias de investigación cualitativa. Barcelona: Gedisa. 